\title{
Dos Zapatas televisivos.
}

La reiteración de usos simbólicos heredados*

\author{
$\approx$ \\ Two Television Zapatas. \\ The Reiteration of Inherited Symbolic Uses
}

\author{
Adrien Charlois Allende \\ Universidad de Guadalajara \\ México \\ Correo: adriencharlois@gmail.com \\ ORCID: https://orcid.org/0000-0002-0566-0126 \\ DOI: 10.48102/hyg.vi58.393
}

Artículo recibido: 02/03/202I

Artículo aceptado: 26/06/202I

ABSTRACT

The Federal Government of Mexico declared 2019 as the "Year of the Southern Leader. Emiliano Zapata Salazar" on the occasion of the centenary of his murder. Not only did the Government tried to link itself to the social movement led by Zapata, but also established an invitation to review the character. This text intends to contribute to the analysis by reviewing the construction of his figure in national television fiction. Senda de gloria, a 1987 telenovela, and El Encanto del águila, a miniseries from 2011, are two cases through which the relationship between the television constitution of the character and the historiographic construction of the Zapatismo is reviewed. The analysis leads us to show the reiterations of differentiated symbols in two fictions of different temporality, from the relationship between television production and the historiographic environment of the moment. In this sense, changes in the representation of the past on television are part of the history of the medium itself.

Key Words: Zapata, Television, Television Fiction, Historiography.

* Este trabajo no hubiera sido posible sin la colaboración de Daniel García Navarro. 


\section{RESUMEN}

El gobierno federal de México declaró a 2019 como el "Año del Caudillo del Sur. Emiliano Zapata Salazar" para conmemorar el centenario de su asesinato. No sólo intentaba vincularse al movimiento social liderado por el suriano, sino que establecía una invitación para la revisión del personaje.

El presente artículo pretende contribuir al análisis de Zapata mediante la revisión de la construcción de su figura en la ficción televisiva nacional. Senda de gloria, telenovela de 1987, y El encanto del águila, miniserie de 2011, son dos casos a través de los cuales se estudia la relación entre la constitución televisiva del personaje y la construcción historiográfica del zapatismo. El análisis nos lleva a evidenciar la reiteraciones de símbolos diferenciados en dos ficciones de distinta temporalidad, desde el vínculo entre la producción televisiva y el ambiente historiográfico del momento. En este sentido, los cambios en la representación del pasado en televisión forman parte de la historia del propio medio.

Palabras clave: Zapata, televisión, ficción televisiva, historiografía.

Toda conmemoración que se precie, siempre tiene un espacio dedicado a la revisión historiográfica del tema a festejar. Estos esfuerzos académicos, a menudo prescinden de revisar los discursos sobre el pasado que no provengan de la misma disciplina o, en muchos casos, del arte nacional. Una de esas revisiones pendientes, suelen ser las que abordan a los medios de comunicación masiva como enunciadores cotidianos de versiones del pasado. 2019, nombrado "Año del Caudillo del Sur. Emiliano Zapata Salazar" por el gobierno federal, no fue la excepción.

El contexto celebratorio, la invitación a repensar a Zapata, pareció un espacio pertinente para voltear a revisar dos producciones televisivas, de distintos presentes, en las que Emiliano Zapata es representado como parte del movimiento revolucionario, como héroe nacional. La idea, en ese sentido, es observar cómo, desde la ficción televisiva, un personaje histórico es resignificado a partir de la reiteración de símbolos asociados con distintos Zapatas 
construidos a lo largo de cien años desde su muerte. Con la incorporación de estos análisis, los recuentos historiográficos quedan más completos, incluyendo productos de historia popular en el universo de formas de recuerdos posibles.

Las conmemoraciones son momentos en que el pasado se vuelve presente y que, por lo mismo, proveen de nuevos marcos reflexivos para todo lo que ya se ha explicado. Es, en ese sentido, que las representaciones de los medios masivos toman importancia. Su popularidad entre las audiencias televisivas las vuelve relevantes como agentes de memoria.

Para dar cuenta de lo anterior se seleccionaron dos ficciones transmitidas por la mayor televisora del país, Televisa: Senda de gloria ${ }^{1}$ (1987) y El encanto del águila ${ }^{2}$ (2011). ${ }^{3}$ Ambas surgen en contextos políticos y mediáticos distintos. Senda de gloria, una telenovela histórica sobre la Revolución mexicana, que abarca de 1916 a 1940, fue producida a fines de los años ochenta, un momento ríspido de la política mexicana. El Partido Revolucionario Institucional (PRI) daba en ese momento un viraje al neoliberalismo con el fin de escapar de los efectos desastrosos de las políticas populistas de los setenta y ochenta. Como parte de esta transformación, se impuso un candidato para las elecciones presidenciales de 1988, que representaba al grupo de tecnócratas más conservadores en términos económicos. Dentro del partido, una corriente en desacuerdo provocó una escisión que se materializaría con su salida de la institución y la formación, apoyada por partidos de izquierda, de un frente que contendería contra el candidato oficial.

${ }^{1}$ Ernesto Alonso, prod., Senda de gloria, dirigida por Raúl Araiza (1987; México: Televisa, emitido del 26 de marzo al 2 de octubre de 1987), televisión abierta.

2 Bernardo Gómez, Leopoldo Gómez y Pedro Torres, prods., El encanto del águila, dirigida por Mafer Suárez y Gerardo Tort (2011; México: Televisa, emitido del 15 de noviembre al 1 de diciembre del 2011), televisión abierta.

${ }^{3}$ Además de éstas, Televisa representó a Zapata en la telenovela de Ernesto Alonso y Miguel Alemán Velasco, prods., La Constitución, dirigida por Raúl Araiza (1970; México: Telesistema Mexicano, 5 de febrero de 1970), televisión abierta. Sin embargo, es sumamente difícil encontrarla para su análisis.

Dos Zapatas televisivos. La reiteración de usos simbólicos heredados / I 35 
En este marco político, un relato sobre la Revolución, producido por Televisa, con apoyo de instancias gubernamentales, levantaba sospechas sobre las posibilidades laudatorias del relato.

Senda de gloria fue la realización máxima de una tradición de telenovelas históricas producidas por Ernesto Alonso que comenzó con La tormenta, en 1967, y que terminó con La antorcha encendida, en 1994, cuya principal estrategia fue entremezclar momentos de la historia nacional con relatos ficcionales paralelos. Con la asesoría de Fausto Zerón Medina, y con guion de Miguel Sabido, relataba los avatares de la familia Álvarez, cuyo patriarca operaba como vínculo con la política nacional, a la vez que como voz narradora de la historia revolucionaria. La estrategia narrativa ayudaba a complejizar el relato de los sucesos políticos y sociales al incorporar, a través de distintos personajes, posturas encontradas en diferentes momentos del proceso.

La gran cantidad de presupuesto proveniente de instancias gubernamentales ayudó a salirse del esquema de las tradicionales telenovelas, incorporando así grandes escenas de batallas, filmaciones en exteriores y una rica ambientación de época. Esta telenovela fue un ejemplo característico del tipo de producciones sobre el pasado realizadas durante la etapa monopólica de la empresa. Aunque no se puede dar por hecho que, debido a la relación directa entre la televisora y el partido en el gobierno, sus representaciones históricas fueran oficiales, lo cierto es que la falta de competencia comercial permitía tener un mejor control sobre el tipo de significados producidos.

La propia historia de este tipo de telenovelas, en las que un solo productor desarrolló sus elementos narrativos y estilísticos más importantes, evidencia que, a partir de reclamos por parte del gobierno, ${ }^{4}$ se pudo ir consolidando un formato que utilizaba los

${ }^{4}$ En 1965, Ernesto Alonso experimentó con la realización de Maximiliano y Carlota, dirigida por Ernesto Alonso (1965; México, Televisa, 1965), televisión abierta. Se melodramatizó la vida de los personajes históricos a través de la clásica oposición entre los buenos (los emperadores) y los malos (Benito Juárez). 
recursos narrativos de la clásica telenovela con historias evidentemente extraídas del discurso oficial. Ello permitió continuar con el exitoso melodrama como estrategia comercial, manteniendo las buenas relaciones con el gobierno a través de representacciones permitidas, controladas desde la Secretaría de Gobernación. Sin embargo, el hecho de que Alonso se asesorara con historiadores como Fausto Zerón, en el caso de Senda de gloria daba cierta libertad para incluir temas que ya estaban en la agenda académica (como la Cristiada), complejizándolos a través de la estrategia de opuestos maniqueos del melodrama, pero con el cuidado de no despertar la ira de la censura.

La estrategia de Televisa se expandiría en los años noventa a través de la comercialización de versiones de colección. En el caso de Senda de gloria, puso a la venta una versión recortada de 36 horas, en DVD y vHs, en la cual se sustenta el análisis de este texto.

Por su parte, El encanto del águila, fue producida en un contexto conmemorativo por el centenario de la Revolución, aunque su transmisión se dio un año después del festejo, en 2011. Televisa se sumó a la celebración con una producción que abandonaba el estilo telenovelero para asumirse como una miniserie generada por el área de noticieros de la cadena. Con ello prometía calidad visual, guiones más atractivos y el apoyo de un círculo de historiadores que sugería un "apego a la verdad".

En un contexto completamente diferente, en el cual Televisa no sólo competía con TvAzteca, sino en el que se anunciaba la llegada de servicios voD (sigla en inglés para el video bajo demanda),

Ante esta osadía, Alonso recibió la orden de modificar el guion original, por lo que decidió terminar precipitadamente con la telenovela. En 1967, el productor intentaría resarcir su "error" con la telenovela La tormenta, dirigida por Ernesto Alonso y Raúl Araiza (1967; México, Televisa, 1967), televisión abierta, la primera en ser producida con fondos del gobierno mexicano y primera telenovela histórica en la que participaron Miguel Sabido, Eduardo Lizalde y Raúl Araiza. La incorporación de estos personajes fue evidente en el uso del recurso narrativo de historias paralelas que caracterizaría a las telenovelas históricas hasta Senda de gloria. 
en especial Netflix, ${ }^{5}$ se lanzó un producto conmemorativo que pretendía competir con el éxito de series de alto valor de producción. Las audiencias, cansadas ya del estilo telenovelero que llevaba unos ańos perdiendo rating, ${ }^{6}$ parecían estar ávidas de nuevas visualidades, nuevas estéticas, otros discursos. En este contexto comercial, la idea de una serie de alto valor permitía a la televisora, por un lado, participar del ambiente celebratorio de 2010, por el otro, idear una transición en sus modelos de producción en la cual la famosa fábrica de telenovelas debía competir con otras áreas de la televisora para producir ficción de calidad. A pesar del momento distinto, la compañía continuó con la estrategia de vender después el producto en una colección de CD, además de promocionarlo en su nueva plataforma voD, Blim. En sentido parecido, el nuevo formato de miniserie se adaptaba mejor a los nuevos consumos de narrativas fragmentadas en boga, que se oponían a las grandes producciones que exigen lealtad constante a sus audiencias y que reiteran grandes narrativas oficiales respecto a los sucesos representados.

Dirigida por Mafer Suárez y Gerardo Tort, producida por Pedro Torres y asesorada por Felipe Ávila y Antonio Saborit, la estrategia narrativa de la producción fue la del individuo como motor de la historia. Las propias contradicciones de los héroes intentaban reflejar el contexto social y cultural del momento narrado, por lo que el melodrama continuó como la estructura básica de narración. El producto fue una miniserie de 13 capítulos de 22 minutos cada uno, que abarcaba desde el levantamiento

${ }^{5}$ El servicio fue lanzado en el mismo 2011 en México, con un catálogo que en un principio incluía productos de Televisa.

${ }^{6}$ En 2010 y 2011, Gritos de muerte y libertad, dirigida por Gerardo Tort (2010; México, Televisa, emitido del 30 de agosto al 16 de septiembre del 2010), televisión abierta, y El encanto del águila, dir. por Gómez, 2011, estuvieron entre las diez ficciones más vistas por la audiencia mexicana, con los lugares 10 y 6 respectivamente. La tendencia a la baja del rating de las telenovelas está bastante bien retratado en los Anuarios del Observatorio Iberoamericano de Ficción Televisiva. 
maderista hasta el gobierno de Plutarco Elías Calles.

El encanto del águila salió en el colofón de un par de sexenios en que gobernó el conservador Partido Acción Nacional (PAN). Ninguno de los dos presidentes panistas (Vicente Fox, 20002006, y Felipe Calderón, 2006-2012) se sentían particularmente identificados con la Revolución mexicana, y mucho menos con héroes populares como Emiliano Zapata. En ese sentido, no se intuía una particular preocupación gubernamental por el tipo de discursos al respecto que pudieran surgir de una televisora. Pero también se aproximaban las elecciones presidenciales de 2012, en las que el PRI retomaría el poder, con fuertes evidencias de apoyo de la misma televisora productora (de hecho, no pocos de los comerciales transmitidos durante la emisión eran del gobierno del Estado de México). En ese sentido, un relato sobre el proceso revolucionario podría ser visto como un recuento de los orígenes, en el cual se justificaba el regreso al poder de esta institución política. No parece haber habido ningún control gubernamental en las representaciones históricas hechas en la serie. Por ello mismo, hubo mucho mayor libertad para representaciones que abrevaron de relatos no oficiales y que, en no pocos sentidos, dialogaban con debates académicos respecto a personajes y procesos.

El uso de ciertos héroes en momentos específicos no ha sido nada nuevo en la relación entre política e historia, o memoria. En ese sentido, parece interesante partir de la relación entre representaciones del pasado y usos políticos, como una veta que guíe la revisión historiográfica de Emiliano Zapata. Para este trabajo, a través de un análisis de contenido cualitativo en medios, que rescata tanto el diálogo como la imagen, se ha tratado de hacer evidentes ciertas representaciones del héroe con el fin de establecer las relaciones entre el momento, la producción televisiva en que se representa y las posibles interpretaciones derivadas los diferentes usos que la figura ha tenido en el tiempo. A partir de la idea de que toda representación se alimenta de matrices de sentido previas, se ha procurado establecer los vínculos entre las figuras te- 
levisadas y las historiografías previas. En esta lógica metodológica se plantea este texto.

\section{ZAPATA A LO LARGO DE UN SIGLO...}

Antes de entrar de lleno al análisis de la figura de Zapata en televisión, hay que partir de una revisión de la forma en que el mito del Caudillo del Sur se fue construyendo desde el momento mismo de su asesinato. Una vista panorámica de la constitución del héroe, más allá de la historiografía académica, permite establecer conexiones con el momento de una representación específica.

El mito de Zapata ha tenido básicamente dos usos: uno oficial y uno popular.' Estas dos formas de recuerdo permitieron que la figura del suriano se convirtiera en propiedad de todos y de nadie, tejiendo una red de símbolos y significados compartidos. En su análisis de la famosa foto de Zapata en traje de charro, Vargas Santiago ${ }^{8}$ plantea que la imagen permite observar esos dos usos fusionados al revelar, primero, una estrategia por civilizar al líder frente las elites nacionales posrevolucionarias y, en segundo orden, la canonización posterior del héroe popular y la circulación del símbolo a nivel nacional.

En esta última perspectiva Zapata es un mártir, por lo que el asesinato a traición por parte del general Jesús Guajardo (a la sazón coronel) establece la condición de su existencia simbólica. Tras su muerte, un culto local comenzó a fraguarse a partir de la relación entre el héroe y las condiciones sociales que le dieron origen, lo que lo vinculó con la idea de "pueblo traicionado". El

7 Samuel Brunk, "The Eyes of Emiliano Zapata", en Heroes and Hero Cults in Latin America, ed. de Samuel Brunk y Ben Fallaw (Austin: University of Texas Press, 2006), 119-120.

${ }^{8}$ Luis Adrián Vargas Santiago, "Emiliano Zapata: cuerpo, tierra, cautiverio”, en El éxodo mexicano. Los héroes en la mira del arte, ed. de Jaime Cuadriello (México: Museo Nacional del Arte/unam, 2010), 441-442. 
crimen ofreció una narrativa en la que fuerzas oscuras se oponen al beneficio popular. A partir de ahí Zapata resultó políticamente útil en términos simbólicos para la posrevolución.

A su vez, la relación de cercanía de Emiliano Zapata con los suyos, con su tierra, con su condición de origen, lo vinculó de manera simbólica con dos elementos de fuerte potencial místico: el campo (la naturaleza y su explotación) y el mundo indígena. Aunada a su muerte, la lucha zapatista posibilitó la constitución de un símbolo planteado como un semidiós que cambió "al tiempo, al mundo y a la gente [...] [con] rasgos particulares, mezcla de fantasía popular caudillesca decimonónica y de los atributos de los hombres-dioses de raíz prehispánica". ${ }^{9}$ De esta noción se alimentó la visión estatal, ejemplificada a través de la obra mural, con la pretensión de "evangelizar a las bases populares en una religión agrarista y sindical al servicio del Estado". ${ }^{10}$

El uso del símbolo tuvo en la posrevolución una expansión hacia otros lugares del país, que alimentó simbólicamente a movimientos distantes en el tiempo y en el espacio. Pero, más importante, proporcionó una experiencia de identidad a las comunidades campesinas nacionales. ${ }^{11}$ Con ese fin, la tumba en Cuautla estableció un escenario para el recuerdo y la reivindicación, que vinculó al héroe con los anhelos de justicia social, prolongando el mito agrarista e indígena por buena parte del siglo xx.

Las carrilleras, el sombrero, el caballo blanco, el bigote, se asociaron con atributos de humildad, virilidad, sed de justicia y sacrificio. Ejemplo de ello es la famosa fotografía que Cassasola tomó el 6 de diciembre de 1914, cuando villistas y zapatistas tomaron la Ciudad de México, en la cual Zapata está sentado a un lado de la silla presidencial. Esta imagen se convirtió en símbolo

\footnotetext{
9 Salvador Rueda Smithers, "Emiliano Zapata, entre la historia y el mito", en El héroe entre el mito y la historia, coord. de Federico Navarrete y Guilhem Olivier (México: Centro de Estudios Mexicanos y Centroamericanos, 2000), 251-264.

${ }^{10}$ Vargas, "Emiliano Zapata: cuerpo, tierra, cautiverio", 451.

${ }^{11}$ Brunk, "The Eyes of Emiliano Zapata”, 121.
} 
de humildad y desinterés por el poder, propios del pueblo (según la versión oficial).

En su necesidad de legitimidad frente a las masas rurales, Álvaro Obregón intentó atraer a los antiguos zapatistas a su proyecto político liberal. Para ello fomentó la tradición de conmemorar el aniversario de la muerte de Zapata cada 10 de abril. Esta apropiación ayudó a ordenar el culto popular, otorgándole un tiempo y un espacio (Cuautla) de conmemoración. Con ello normaron su uso político a través de la reivindicación de la demanda agrarista, establecieron los límites de lo celebrable y vincularon a los zapatistas con el nuevo proyecto de Estado. Zapata fue útil para darle contenido social al proyecto sonorense de Obregón y Calles, ${ }^{12}$ además de otorgar una línea de continuidad entre la lucha campesina y las políticas del gobierno mexicano.

Plutarco Elías Calles incorporó a los obreros en la elaboración del mito, cargando de símbolos zapatistas a sus proyectos sociales. Ambos presidentes aprovecharon la literatura, los medios masivos, la educación pública, pero sobre todo a las artes plásticas, como forma de expandir, de urbanizar y de estabilizar los significados asociados a la figura, provenientes -muchos- del culto popular. Lo cual se consolidó en 1931, al inscribir el nombre de Zapata, con letras de oro, en el Congreso federal.

A partir de 1934, Lázaro Cárdenas impulsó una masiva reforma agraria que acompañó con la figura del rebelde de Morelos. El proyecto de expansión del Estado a través de la educación socialista y el reparto de tierras, fue aparejado con la edición de obras de intelectuales zapatistas como Gildardo Magaña, Jesús Sotelo Inclán u Octavio Paz Solórzano, con la creación de conmemoraciones locales o con el nombramiento de organizaciones ejidales por todo el país. Esto se dio en el marco de un objetivo

${ }^{12}$ Felipe Ávila Espinoza, "La batalla por los símbolos. El uso oficial de Zapata", en Historia de Morelos. Tierra, gente, tiempos del sur, t. viI, El zapatismo, coord. de Horacio Crespo (México: H. Congreso del Estado de Morelos, 2009), 409. 
político que se orientaba al indigenismo, en donde Zapata encajaba en un proyecto que educaba respecto a "lo mexicano". ${ }^{13}$

Esta nueva memoria de Estado fue útil en la conversión de campesinos en parte integral de la estructura de los gobiernos posrevolucionarios. La creación de la Confederación Nacional Campesina (CNC) en 1938, bajo el lema de "Tierra y Libertad", fue un paso importante en la conformación de lo que luego se llamaría "la gran familia revolucionaria", la cual fue el fundamento para estructurar el dominante Partido Revolucionario Institucional. Ello normó las relaciones entre el campesinado y el Estado, vinculó una idea estatal sobre lo indígena y campesino con un tiempo-espacio ritual, a la vez que con sus políticas agrarias.

A partir de 1940 ningún presidente dejaría de asistir, por lo menos una vez durante su mandato, al aniversario luctuoso de $\mathrm{Za}$ pata. Incluso los mandatarios más conservadores, como Manuel Ávila Camacho y Miguel Alemán, mantuvieron la tradición. Para Felipe Ávila Espinoza ${ }^{14}$ cuanto más alejadas fueron las políticas estatales de los postulados de reforma social, igualdad y justicia, más necesaria era la reivindicación del símbolo. Utilizando la retórica del mito popular, llegaron a considerar a Zapata como alma y esencia de lo genuinamente mexicano, cuyo espíritu renació para servir de guía a los campesinos nacionales. Sin embargo, el culto público de Zapata, dejó poco a poco de estar en manos del gobierno, para ser controlado por sindicatos y confederaciones campesinas.

Presidentes populistas como Luis Echeverría y José López Portillo explotaron la figura zapatista como representante del Tercer Mundo y trasladaron la ceremonia al escenario del asesinato: la hacienda de Chinameca, en Morelos. Con ello intentaban disputar el uso simbólico frente a campesinos inconformes por los fracasos de sus políticas agrarias y económicas.

${ }^{13}$ Rueda, "Emiliano Zapata entre la historia y el mito", 33.

${ }^{14}$ Ávila, "La batalla por los símbolos. El uso oficial de Zapata”, 415.

Dos Zapatas televisivos. La reiteración de usos simbólicos heredados / I43 
A contrapelo de lo que se podría pensar, la llegada de los gobiernos neoliberales a principios de los ochenta no disminuyó el fervor zapatista del Estado mexicano. Carlos Salinas de Gortari puso bajo la figura del suriano a su gobierno y justificó con ello sus reformas al artículo 27 de la Constitución, tendientes a la liberalización de las tierras ejidales, tratando de modernizar los ideales del héroe revolucionario. Este control de la figura se hizo más apremiante con el alza del movimiento encabezado por Cuauhtémoc Cárdenas al interior del PRI a fines de los ochenta, y el alzamiento del Ejército Zapatista de Liberación Nacional en el sur del país a mediados de los 90, ${ }^{15}$ los cuales disputaban al gobierno la legitimidad sobre las demandas sociales de grupos históricamente marginados.

Fue la llegada del PAN al poder, en el año 2000, la que por fin le dio un respiro a Zapata en el ánimo controlador del Estado. El panismo no vio la necesidad de gestionar el mito, dejando la conmemoración en manos de otros actores, como la televisión o el cine. En el caso de ésta, a lo largo del siglo xx se mantuvo al caudillo suriano como una figura de interés que explicaba una parte de la historia nacional, aquella que vincula lo indígena, sus mitos, sus representaciones, con la lucha social constante. Desde ;Viva Zapata! (1952), de Elia Kazan, hasta Zapata, el sueño del héroe (2004), de Alfonso Arau, las películas en torno al personaje navegaron en posturas que engranaban con sentidos ya utilizados: el del símbolo de la resistencia, el del chamán indígena, el del luchador desinteresado. Pero el control del Estado, durante los gobiernos del PRI, fue central en la poca producción en torno a Zapata, al grado de censurar Emiliano Zapata (1970), de Felipe Cazals, a pesar de haber sido un pedido del propio presidente Gustavo Díaz Ordaz. En este sentido, a pesar de ser una figura querida de los mexicanos, los sentidos asociados a ella obligaron al Estado a contener toda representación que se diera por fuera de sus propios canales.

${ }^{15}$ Ávila, "La batalla por los símbolos. El uso oficial de Zapata”, 415.

I 44 / Adrien Charlois Allende 
En el caso de la televisión, además de Senda de gloria y el Encanto del águila, La constitución (1970) y El vuelo del águila (1994) también hicieron uso de la figura zapatista; sin embargo, dado que es difícil conseguir La constitución, y que El vuelo del águila está centrada en la vida de Porfirio Díaz, y en ella Zapata no juega un rol central, se decidió no incluirlos en el análisis.

Dos usos principales (popular y estatal) ha tenido la figura del líder agrarista. Perspectivas que operan como marco de reiteración de imágenes, pasajes y, especialmente, significados asociados al héroe. No estamos ante perspectivas antagónicas, sino ante narrativas que se han complementado unas a otras, además de la proveniente del análisis académico, y que operan como material base sobre el que la ficción televisiva construiría su propia versión de ese pasado.

\section{Un Zapata de telenovela: SENDA DE GLORIA}

La representación de Zapata en Senda de gloria tiene como núcleo la relación del caudillo con la lucha por los derechos agrarios de los campesinos mexicanos. Si bien algunas frases o elementos icónicos resaltan algún otro aspecto de las múltiples facetas de Zapata, el discurso, digamos "ecuánime” y centrado en la política que propone la telenovela limita la existencia de ese caudillo imaginado desde elementos metafísicos en el culto popular.

En la lógica narrativa de la telenovela histórica, la dimensión popular del símbolo se encuentra en la historia ficcional de la familia Álvarez. La primera mención la hace Nacha, la criada de la familia. Frente al general Álvarez, patriarca familiar, ella hace saber que aborrece a Carranza, "viejo barbas de chivo". El general se niega a discutir de política con la criada, lo cual sirve para poner sobre la mesa la perspectiva de que Zapata pertenece al ámbito del pueblo: “¿Y por qué no va a discutir conmigo?, si yo soy del pueblo. ¡Sé de política! Usted nada más quiere hablar con políti- 
cos, con generales, con presidentes. Además, [Carranza] será muy presidente, pero yo fui zapatista" ${ }^{16}$ Nacha establece el lugar que confiere significado a Zapata: él es del pueblo y no de los políticos. El héroe se revela como símbolo de la humildad y de la falta de ambición política, recuperando así parte del uso simbólico que la posrevolución le dio al caudillo suriano.

Esta distancia marcada entre Zapata y "los políticos" continúa con Obregón. El morelense dice a uno de sus soldados: “¿Y qué historias son ésas de lo que dice el general Obregón? ¿Qué? ¿Tú sabes algo?”. El soldado intuye que el militar sonorense buscará la presidencia, y Zapata se lo confirma al confesarle que solicitó su apoyo. Pero en su desconfianza, el suriano sabe que "lo que quieren todos es acabar con nosotros para no cumplir nada de lo que la Revolución le prometió al pueblo". ${ }^{17}$

La anterior es una confesión poderosa en un contexto como el de 1987-1988 en México; sin embargo, el uso oficialista de Zapata, a través de años de priismo, permite recordar que las promesas no cumplidas serán reivindicadas mucho después por el mismo Obregón y el partido formado por los sonorenses. El Caudillo del Sur, entonces, sólo es un reclamo que nace de su desconfianza: "Obregón o el que sea va a ser lo mismo", ${ }^{18}$ de esa distancia con los políticos que se revela como sana. Con el alejamiento de "los campesinos", representados por Zapata, del debate y la discusión sobre el poder, se despolitiza su participación en la lucha. Sus reclamos parecen justos mientras no intenten llegar al poder; su desconfianza es entendible.

El vínculo del mito zapatista con lo agrario, lo rural, viene no sólo de su lucha por el reparto de tierras, sino de su propio conocimiento del medio. Senda de gloria no pudo evitar esta faceta central del personaje; sin ella no se entendería. Pero, en el ánimo

16 "Emboscada y muerte de Zapata", temporada 1, episodio 1, Senda de gloria, dirigida por Raúl Araiza, Televisa, 1987, mins: 51:55-56:15.

17 "Emboscada y muerte de Zapata", dir. por Araiza, mins: 1:17:00-1:21:33.

18 "Emboscada y muerte de Zapata", dir. por Araiza, mins:1:14:52-1:16:36. 
de evitar polémica, hicieron un Zapata justo con ambos bandos (hacendados y campesinos). Mientras descansa, uno de sus soldados le trae a un ingeniero capturado por sus tropas. Explica al caudillo que están haciendo planos y deslindes, a lo que el suriano responde "desde antes de la Revolución yo he estado peleando por todo esto. Los ejidos no se devuelven a los pueblos, la tierra no se entrega a los campesinos. Y no es como la gente cree que yo no quiero que los hacendados tengan sus tierras. No, no, no. Lo que yo quiero es que no se apropien de las que no son de ellos". ${ }^{19}$ Así, el Zapata telenovelado se distancia de los usos que de su figura han hecho otras luchas a lo largo del siglo xx. No se trata de combatir en contra de los hacendados, sino de una injusticia como lo son el robo y la apropiación de tierras. ¿Quién se negaría a ello? El héroe del sur cuestiona la utilidad de los planos, hace gala del conocimiento de su tierra para demostrar el punto respecto a los hacendados. Cuestiona al ingeniero por una piedra que aparece en los planos "¿Una piedra? ¿Esto es una piedra? ¿Es una piedra grande? ¿Así? ¿Así? ¿ ¿O como aquel monte que está allá? Las piedras caminan, ingeniero, ¿no lo sabía? [...] las mueven por las noches los caciques [...] donde le conviene al hacendado". ${ }^{20}$

La presencia de Zapata en Senda de gloria es relativamente breve. La telenovela comienza su trama del pasado revolucionario en 1916, por lo que el caudillo aparece sobre todo para morir. No es de extrañar ello ya que, como ya se mencionó, la muerte del héroe es fundamental en la concepción y difusión del símbolo. Detrás de esta perspectiva está la idea de que el suriano, alejado de la ambición política, luchador por una causa noble y justa, es traicionado por un gobernante (Carranza) que no representa el espíritu de la Revolución concebida por el grupo de sonorenses (Obregón, Calles, etc.).

19 "Emboscada y muerte de Zapata", dir. por Araiza, mins: 59:52-1:06:16.

20 "Emboscada y muerte de Zapata", dir. por Araiza, mins: 59:52-1:06:16.

Dos Zapatas televisivos. La reiteración de usos simbólicos heredados / 147 
La muerte viene intuida ya por Zapata. El coronel Guajardo se pone en contacto con el caudillo para ofrecerle pasarse a su bando con tropa, armas y municiones. A pesar de la desconfianza, el caudillo no ve otra salida más que la alianza. Sin embargo, el propio héroe sabe que algo ocurrirá: “esa hacienda, Chinameca, le tengo ojeriza [...] ahí por poco me matan en 1911, me sorprendieron. Me escapé de milagro por los cańaverales en la noche. Incendiaron todo el campo para hallarme. De puro milagro me escapé. [A e]sa hacienda le tengo ojeriza". ${ }^{21}$

La tensión aumenta mientras se mantienen los contactos cordiales con Guajardo. Zapata se enfila con los suyos hacia Chinameca, pero los deja afuera de la hacienda para entrar sólo con diez hombres. La escena por sí misma no es dramática, no hay palabras, sólo el héroe entrando con los suyos, encuentra de frente a Guajardo. En un instante, el coronel traicionero mata a un zapatista que se encuentra a su lado, Zapata ve que no hay salida; unos soldados salen por el techo y lo acribillan. Como recurso técnico, la producción de Senda de gloria decidió congelar la imagen del caudillo muerto mientras torna a sepia. La imagen se vuelve documento, testimonio inapelable de la traición, marcada por el indicador espaciotemporal "Hacienda de Chinameca. 10 de Abril de 1919”.

Como en el resto de la telenovela, la voz ecuánime del general Álvarez proporciona el tono en que debe ser reflexionado el héroe: "Yo no puedo dejar de admirar la terquedad de un hombre que luchó por lo que creyó justo; por sus principios". ${ }^{22}$ Así, la última mención al héroe no es más que un reconocimiento por parte de los sectores opuestos a él (Álvarez se identifica como carrancista), a los elementos que representa el símbolo en que se convertirá Zapata en el siglo xx: terquedad, lucha, sacrificio, justicia.

21 "Emboscada y muerte de Zapata", dir. por Araiza, mins: 1:17:00-1:21:33. 22 "Emboscada y muerte de Zapata", dir. por Araiza, mins: 2:14:18-2:18:15. 
Las menciones a Zapata se van diluyendo en el resto de la telenovela, pero la referencia al zapatismo tendrá sus momentos. Éstos se centran en dos elementos vinculados, mencionados por la historiografía zapatista: el esfuerzo que hizo Obregón por atraer a los zapatistas durante su campaña por la presidencia y la influencia de los ideales zapatistas en la elaboración de leyes y decretos. En estos dos sentidos, el diputado Reséndiz, al debatir el tema agrario en la Cámara de Diputados en 1921, plantea: “creo, ciudadanos diputados, que en este mismo recinto ha quedado claro que el señor presidente Obregón es un agrarista [...] Con justicia Álvaro Obregón es el ejecutor testamentario de Emiliano Zapata. Necesitamos más ejidos y menos política". ${ }^{23}$ Con ello, Senda de gloria cierra el círculo simbólico que permitió a los presidentes, durante años, declararse sucesores de la lucha terca, justa, humilde que representó el Zapata simbólico, reiterando así la importancia de la continuidad del régimen que, en el momento de la producción, luchaba en las elecciones por imponer nuevamente a un candidato presidencial.

\section{Un Zapata Conmemorativo: EL ENCANTO DEL ÁGUILA}

El encanto del águila se presentó como un relato abarcador del periodo revolucionario que va desde el levantamiento maderista en 1910 hasta el fin de la presidencia de Plutarco Elías Calles en 1928. El argumento se divide en episodios que relatan la participación de uno u otro personaje importante, dentro de los que es posible distinguir un capítulo dedicado a Zapata ("La silla incómoda") y una serie de episodios en las que la figura aparece momentáneamente ("Un chacal en el palacio", "Las batallas fratricidas" y "De la Constitución a la rebelión", en el cual asesinan al suriano). En estos capítulos la trama se centra en la lucha contra

23 "Periodo presidencial de Álvaro Obregón", temporada 1, episodio 4, Senda de gloria, dirigida por Raúl Araiza, Televisa, 1987, mins: 5:18:35-5:22:47.

Dos Zapatas televisivos. La reiteración de usos simbólicos heredados / I 49 
Victoriano Huerta, la entrada de Villa y Zapata a la Ciudad de México (capítulo central) y el asesinato del héroe.

Quizá porque la producción tuvo un círculo mucho más amplio de asesores históricos, el Zapata de la miniserie quedó menos acartonado y vinculado a su propia muerte, sin que ésta deje de ser un elemento discursivo central. Su primera aparición establece la relación entre los usos simbólicos popular y político, a través de la reiteración de una imagen, la del Zapata en traje de charro. Ataviado como tal, el suriano escucha de Otilio Montaño la lectura de la carta que le envía Victoriano Huerta solicitándole apoyo para su gobierno (que, sabemos, fue usurpador) ante la amenaza de invasión estadounidense. Zapata voltea de modo despacioso, fuma un puro, con total seriedad dice "yo defiendo a México, pero no junto a ese chacal". ${ }^{24}$ Su nacionalismo está planteado, su postura "del lado correcto de la historia" revolucionaria es evidente. Pero, por otro lado, minutos más adelante, con la misma postura e imagen, afirma ante la sugerencia de Otilio de unirse a Carranza y los del norte: "nuestra lucha es por la tierra, esta tierra”. ${ }^{25}$ Así pues, Zapata defiende a México, pero su lucha real es por los suyos, por su pueblo, por los campesinos de Morelos. El símbolo comienza a construirse en una relación entre la nación, la tierra y el pueblo, tres elementos esenciales de los usos popular y estatal del Caudillo del Sur.

Esta mezcla representa a Zapata como un líder del pueblo, en el cual la naturaleza (entendida como cercanía a la tierra) se conecta con su vocación justiciera. El capítulo 8, "La silla incómoda", abre con una toma centrada en el movimiento que el viento produce en los cañaverales de Morelos. El campo está siempre presente. La toma se abre y viaja para dejarnos ver que un nińo corre hacia Zapata, quien está recostado con una mujer semidesnuda, en un

24 "Un chacal en el palacio", temporada 1, episodio 6, El encanto del águila, dir. por Mafer Suárez, transmitido el 22 de noviembre del 2011 por Televisa, mins: 9:58-10:45.

25 “Un chacal en el palacio", dir. por Suárez, mins: 13:06-13:52. 
momento romántico. El nińo informa que Villa quiere que entren juntos a la Ciudad de México; el héroe accede. ${ }^{26} \mathrm{Si}$ bien la escena no dice mucho, la relación entre la labor en los cańaverales y las pasiones amorosas del Caudillo permiten asumir, de nuevo, la cercanía con la tierra y con su gente. Siempre ataviados de indígenas folclorizados (la mujer tiene una camisa bordada), los campesinos zapatistas son un vínculo entre el héroe, el pasado prehispánico y el campo nacional.

Esta idea del zapatismo como garante de la justicia en el campo se resalta cuando, camino a la Ciudad de México, los generales Rodolfo Fierro (villista) y Pioquinto Galis (zapatista) platican las diferencias que encuentran entre ellos. ${ }^{27}$ Fierro no puede comprender que vayan vestidos de manta. Cuando Galis pregunta qué siembran en el norte, Fierro responde que él nada, que trabajaba en el ferrocarril. La conversación subraya las diferencias entre el campesinado, en el sur, y los trabajadores del norte. El zapatismo mantiene vigente su identificación con la lucha campesina en exclusiva, que se marca en cada momento posible. Visualmente el campesinado, relacionado con la tradición indígena, mantiene un cierto nivel de exotismo para el resto de los revolucionarios. Diferentes escenas lo subrayan en la vestimenta, en las costumbres culinarias, pero también en el repetido mote de "bárbaros" puesto en la voz de Obregón o Carranza.

Ya reunidos en Xochimilco, Zapata y Villa conversan sus posturas. La escena es rica en vincular las dos luchas a partir del concepto de "pueblo". Para ambos generales, su proceder se opone al de los militares "perfumados" de la otra revolución (Obregón, Carranza, etc.). Al reconocerse entre ellos, Villa y Zapata se apartan de sus hombres, un plano medio nos enfoca en la palabra. Villa cuestiona al suriano sobre el deslinde entre su lucha y la de

26 "La silla incómoda", temporada 1, episodio 8, El encanto del águila, dir. por Mafer Suárez, transmitido el 24 de noviembre del 2011 por Televisa, mins: 0:00$1: 24$.

27 "La silla incómoda”, dir. por Suárez, mins: 8:50-10:17.

Dos Zapatas televisivos. La reiteración de usos simbólicos heredados / I5 | 
Carranza, Zapata concuerda con el norteño, quien pregunta: "sólo para confirmar, ¿̨nuestra causa sigue siendo el pueblo?”; Zapata remata afirmativamente: "el repartir la tierra". ${ }^{28}$ Ahí no queda duda, el Zapata de El encanto del águila continúa su tradición simbólica: pueblo, tierra, pasado indígena se vuelven a sumir en el símbolo historiográfico. El argumento toma tintes místicos que, capítulos más adelante, reafirman el vínculo cuando Villa es derrotado por Obregón en el Bajío. Zapata presiente que a continuación vendrán por él y los suyos, por lo que propone refugiarse en la sierra de Morelos. Genovevo de la $\mathrm{O}$ pide que se queden a defender sus tierras; Zapata, paternal, toma del hombro a su militar y contesta: "Genovevo, ¿cuándo van a entender que la tierra no nos pertenece? Nosotros le pertenecemos a ella". ${ }^{29}$ La frase cierra la pinza de la representación, el militar se convierte en profeta, las luchas personales se quedan en un segundo plano cuando la justicia está vinculada a los destinos de la naturaleza.

La escena con Villa continúa, rica en estereotipos sobre la fiesta popular mexicana. Planos picados y travellings describen todo un homenaje al folclorismo clásico mexicano. Pero lo importante está en la constante reafirmación, por medio del diálogo, de la existencia de un nosotros pobre, que se enfrenta a unos otros ricos. Ya en el banquete, villistas y zapatistas intercambian posturas. ${ }^{30}$ Villa comenta: "él [Carranza] y los suyos siempre han dormido en almohada blandita ¿quién les va a creer que son amigos de los pobres? [...] pero aquí nos ponemos de acuerdo y queda arreglado el destino de México". Pero Zapata reitera su humildad respondiendo que no quiere cargos públicos, y sentencia: "por eso yo le digo a los amigos 'mucho cuidado quién llegue a la silla, y si no hace justicia le cae el machete"”. Zapata pone el tono, su

\footnotetext{
28 "La silla incómoda”, dir. por Suárez, mins:11:05-11:59.

29 "Las batallas fratricidas", temporada 1, episodio 9, El encanto del águila, dir. por Mafer Suárez, transmitido el 25 de noviembre del 2011 por Televisa, mins: 19:40-20:15.

30 “La silla incómoda”, dir. por Mafer Suárez, mins: 11:05-11:59.
} 
función es vigilar al poder. El machete no es más que el símbolo más evidente que el pueblo tiene para esa función. Al final, Villa confirma esta vocación justiciera: "mi ilusión es repartir la tierra de los riquillos [...] jal pueblo le corresponde la tierra! [...] Es hora de que se haga justicia, yo estoy de acuerdo en secundar el Plan de Ayala, que la tierra se reparta entre el pueblo". ${ }^{31}$ En estos diálogos, ambos héroes coinciden en la vocación de su lucha. La idea de humildad y falta de ambición política entre el pueblo hace aún más noble la tarea, y más trágica la traición al símbolo.

Para remarcar el argumento, El encanto del águila vuelve a utilizar la famosa fotografía de los dos generales en Palacio Nacional. Unos soldados traen la silla presidencial al salón en el que se encuentran los héroes. Al llegar la silla Zapata dice a Villa: "pido autorización para quemarla [...] la gente piensa que está embrujada. Los candidatos prometen, nomás se sientan y se les olvida todo". Villa ríe mientras se sienta en ella, Zapata se acomoda a un lado, sin ambición de poder. La escena termina con la toma de la famosa foto, el plano se torna a blanco y negro, inmortalizando la idea.

A los gobiernos posrevolucionarios el general suriano sólo les fue útil ya muerto. La fuerza simbólica, como bien lo remarcan los estudios al respecto, creció tras su muerte. En la miniserie, Zapata también parece intuir su muerte. En el inicio de "De la Constitución a la rebelión", un travelling nos lleva a un Zapata dubitativo que espera para responder a Pioquinto Galis cuando éste le comenta el distanciamiento entre Guajardo, el traidor, y el general Pablo González (representado en una escena previa). Zapata opta por cobijar al traidor. La magnanimidad del héroe contrasta con el resquemor que eso causa en su amante: "Emiliano ¿pa’ qué te traes a uno que ni conoces?”. ${ }^{32}$

31 "La silla incómoda", dir. por Suárez, mins: 12:00-14:43.

32 "De la Constitución a la rebelión", temporada 1, episodio 11, El encanto del águila, dir. por Mafer Suárez, transmitido el 29 de noviembre del 2011 por Televisa, mins: 1:51-2:38.

Dos Zapatas televisivos. La reiteración de usos simbólicos heredados / I 53 
La ingenuidad de Zapata es puesta en evidencia, pero él insiste en la incorporación, tras sugerir condiciones. Una vez cumplidas Guajardo es recibido por Zapata. El traidor exhorta a éste y los suyos a desayunar en Chinameca, donde espera un cargamento de munición. El héroe intuye algo mientras duerme con su amante, despierta como de una pesadilla, exaltado, se sienta el borde de la cama, sudado, su amante lo abraza y besa para apaciguarlo. ${ }^{33}$ Zapata parece sentir y aceptar su destino, sabe que no tiene más opciones, pero también que su muerte es parte de su lucha. Minutos después, los zapatistas, cansados, esperan tensos mientras Guajardo los recibe. El marcador temporal "10 de abril de 1919" pone sobre la pantalla la fecha fatal, el tiempo de muerte y de posterior conmemoración. Desesperado por la espera, Zapata presiente traición. Finalmente, un soldado de Guajardo llega a averiguar si los zapatistas van a bajar. El caudillo, recargado sobre la silla de montar, tras meditar un momento, da la orden de marchar a sus temerosos soldados. Zapata mira al horizonte y sentencia: "Ni modo que a estas alturas nos dé miedo morir". ${ }^{34} \mathrm{El}$ héroe sabe de antemano que la muerte es un destino probable.

La escena del asesinato ${ }^{35}$ no tiene el peso que en Senda de gloria. Un travelling convierte a la audiencia en testigo, Zapata y los suyos entran a caballo. Un marcador reitera "Hacienda de Chinameca, Morelos", mientras las tomas revelan hombres armados escondidos. Zapata se encuentra con Guajardo, quien lo llama para mostrarle "las balas que le tengo". No se percibe tensión, la música no indica nada, sólo un balazo en el pecho y una andanada de disparos por la espalda (la traición) dan paso a un plano tomado desde la propia silla de montar en el que se ve caer al héroe. La sangre corre por el pecho, la cara revela dolor y, por último, el héroe cae al suelo. La música de fondo se torna nostálgica.

33 "De la Constitución a la rebelión”, dir. por Suárez, mins: 5:04-5:27.

34 "De la Constitución a la rebelión", dir. por Suárez, mins: 5:30-6:10.

35 "De la Constitución a la rebelión", dir. por Suárez, mins: 7:11-7:55.

I54 / Adrien Charlois Allende 
Nada de cuadros congelados, que se tornan a sepia o blanco y negro. La muerte de Zapata queda ahí. Sólo los marcadores temporales y la trama dan cuenta de la importancia del héroe que tomó la Ciudad de México junto a Francisco Villa, que luchó contra Victoriano Huerta, que fue traicionado. La serie de símbolos asociados contribuyen a mantener el mito vivo, el del elegante charro que luchó por su tierra, que buscó justicia sin ambicionar el poder. Únicamente la frase final del epílogo del último capítulo de la miniserie recordará a la audiencia que "los anhelos de justicia social que inspiran el movimiento revolucionario siguen vigentes hasta nuestros días", ${ }^{36}$ como un indicio de que hay problemas sin resolver y posibilidades de lograrlo en 2011.

\section{RefLeXiones FinALES}

Las ficciones históricas televisivas no pueden sustraerse del cúmulo de representaciones previas. Los productos analizados no fueron diferentes en su necesidad de reiterar representaciones y sentidos previos, con el fin de regresar al héroe al presente de su enunciación.

Senda de gloria arranca con una perspectiva del pueblo controlada desde el poder de las elites políticas, materializadas en el personaje del general Álvarez. El pueblo personificado por Nacha demanda un uso propio del símbolo a través del concepto de justicia, asociado con las demandas de los más necesitados. Estos significados vinculados son tolerados en tanto no se conviertan en demanda de poder. La negativa del general Álvarez a la discusión no hace sino reafirmar la postura "desde arriba". En 1987 esa idea no tenía nada de inocente, los gobiernos de los setenta y principios de los ochenta se habían convertido en el símbolo

36 "El último caudillo", temporada 1, episodio 13, El encanto del águila, dir. por Mafer Suárez, transmitido el 29 de noviembre del 2011 por Televisa.

Dos Zapatas televisivos. La reiteración de usos simbólicos heredados / I 55 
de la corrupción y la ineficacia del populismo hecho gobierno. Las demandas asociadas a esta forma de política no podían ser permitidas por una elite gobernante que fundaba sus proyectos en el neoliberalismo en boga. No es casual que, muy pronto, se apropiaran del símbolo, a través de la cercanía con cierta academia. Con Zapata en mano, los gobiernos neoliberales validaron sus políticas agrícolas vinculando la idea de propiedad privada con la del reparto de tierras, aunque Zapata y Carlos Salinas no tuvieran en mente el mismo tipo de propiedad.

En este mismo marco, el recelo y la desconfianza entre pueblo y gobierno estaban más que justificadas. Zapata mismo confirma que quieren acabar con ellos (con él) con el fin de no cumplir las promesas hechas al pueblo. Pero el partido en el gobierno jamás se vio a sí mismo como algo distante a éste, de ahí que no se silenciara al héroe, sino que se apropiara desde la propia narrativa en uso.

El encanto del águila ofrece de arranque una versión más "civilizada" del héroe. Si bien el recelo se mantiene, su compromiso con el pueblo se conserva a través de la lucha por "esta tierra". Zapata ya no sólo defiende un ideal social, sino el de una nación en riesgo por un factor externo. A inicios de la segunda década del siglo XxI, el resquemor por la diversidad de demandas sociales se mantenía, pero el Caudillo del Sur ya no parecía un riesgo. Las necesidades del uso simbólico de la figura tenían más que ver con la adecuación de su representación para públicos más urbanos que rurales, para una base social que ya no se significaba a través de corporaciones, como en el siglo $\mathrm{xx}$, sino como individuos trabajadores. Parece que el Zapata "catrín" resultaba más útil en este sentido.

De la misma manera, la cercanía con la tierra, como significado primigenio y popular relacionado con Zapata, resultó ciertamente atractivo en El encanto del águila. Esta veta se explotó a través del exotismo de su figura, vinculando así la referencia justiciera con una idea idílica del campo, y de quienes lo habitan. El regreso a las imágenes bucólicas del campo y a "lo indígena" desde 
el folclor, ya no podía interpelar al "pueblo", entendido como campesinado, sino al público, entendido como ciudadano urbano.

$\mathrm{Al}$ engranar héroe-campo-pasado indígena, por medio de estereotipos reiterados, el Zapata (y el zapatismo) queda más como un bien de consumo que siempre trae aparejado un recuerdo de justicia. Si bien el paso del símbolo rural a lo urbano es previo al momento de la producción, se abandonaron los tradicionales canales creadores de sentido para alimentar otros, como la ficción televisiva, que despolitizan esas relaciones a través de imágenes que recuerdan "el encanto del campo". Lo mismo se podría decir de la fascinación por la inocencia zapatista. La anécdota de la silla presidencial aligera el estrés que provoca "el pueblo" en el poder, permite aparecer a Zapata sin alentar ambiciones, en un contexto en el que la toma de poder por parte del proyecto de izquierda y popular de Andrés Manuel López Obrador era una opción real que atemorizaba a las mismas elites que producen esa ficción.

Esta perspectiva exotizante, condescendiente, no tenía lugar en 1987. Si bien el cambio de política era notorio, el partido en el poder nunca abandonó el control sobre sus héroes. La inocencia y humildad de Zapata no tuvieron especial lugar en Senda de gloria; su cercanía con el campo se materializaría en el debate político, en el vínculo entre Zapata y el sistema de gobierno priista, a través de la relación narrada entre Zapata y Obregón. Las visiones bucólicas de lo rural quedaron fuera, para enfatizar la justicia como centro narrativo de la representación heroica.

Pero, como en todo el relato sobre el héroe, ninguna representación tendría sentido sin su muerte. El asesinato a traición aparece en ambas ficciones. En Senda de gloria, el viraje a sepia de la imagen, inmortaliza la injusticia que ha significado el momento, es crucial para entender el engranaje entre zapatismo y agrarismo de Estado. El que Obregón sea ejecutor testamentario sólo tiene sentido en la muerte, es la forma en que el héroe alcanza condición de mártir a través de la perpetuación de su verdad. En El encanto del águila, la idea martirial no tiene el mismo poder 
y fuerza. La imagen no se congela, su muerte es una parte más del proceso histórico llamado Revolución, sólo explica, despolitizando, "anhelos de justicia social".

Senda de gloria y El encanto del águila no son dos representaciones antagónicas de Zapata. Como todo material historiográfico, el tipo de representación tiene un triple origen: la matriz historiográfica de la que se alimentan, el presente de su enunciación y la conceptualización del público objetivo (esta última fuente es siempre la más difícil de aprehender en el análisis). La imagen de Zapata tiene tradiciones de representación, y de ellas abrevan las producciones, enfatizando, claro, los elementos que mejor dialogan con la situación presente. Ambas ficciones ofrecen dos héroes que se complementan en la propuesta de una sola memoria, la del líder humilde, justo y romántico que se constituyó en casi cien años desde la muerte del suriano. Si bien entre ambas producciones el zapatismo tuvo un renacimiento como idea política en 1994, no parece establecer un diálogo con el símbolo televisivo. Por el contrario, parecería que el Zapata exotizado de 2011 justamente trata de evitar cualquier debate político contemporáneo con el fin de eliminar el vínculo entre la figura y la lucha social de fines del siglo xx. A pesar de que El encanto del águila parece que mantiene la lógica de producción que vincula sistema televisivo y nación, su propuesta parece más dirigida a audiencias que ya no entran en esa relación, gracias a las múltiples planteamientos existentes en internet, y que parecen ver al neozapatismo como algo cada día más lejano. 鹿

\section{Fuentes}

\section{Primarias}

Alemán Velasco, Miguel, prod. La tormenta, dir. por Ernesto Alonso. México: Televisa, transmitida en 1967, Televisión abierta, 1967.

Alemán Velasco, Miguel, prod. Maximiliano y Carlota, dir. por Ernesto Alonso. México: Televisa, transmitida en 1965, Televisión abierta, 1965. 
Alonso, Ernesto, prod. Senda de gloria, dir. por Raúl Araiza. México: Televisa, transmitida del 26 de marzo al 2 de octubre de 1987, Televisión abierta, 1987.

Gómez, Bernardo, Leopoldo Gómez y Pedro Torres, prods. El encanto del águila, dir. por Mafer Suárez y Gerardo Tort. México: El Mall, Televisa, transmitida del 15 de noviembre al 1 de diciembre del 2011, Televisión abierta, 2011.

Gómez, Bernardo y Leopoldo Gómez, prods. Gritos de muerte y libertad, dir. por Gerardo Tort. México: Televisa, transmitida del 30 de agosto al 16 de septiembre del 2010, Televisión abierta, 2010.

\section{Referencias}

Ávila Espinoza, Felipe. "La batalla por los símbolos. El uso oficial de Zapata”. En Historia de Morelos. Tierra, gente, tiempos del sur 1810-1910, t. viI, El zapatismo, ed. de Horacio Crespo, 405-440. México: H. Congreso del Estado de Morelos, 2009.

Brunk, Samuel. "La muerte de Emiliano Zapata y la institucionalización de la Revolución mexicana (1919-1940)”. En Estudios sobre el zapatismo, coord. de Laura Espejel López, 361-386. México: INAH, 2000.

Brunk, Samuel. "The Eyes of Emiliano Zapata”. En Heroes and Hero Cults in Latin America, coord. de Samuel Brunk y Ben Fallaw, 109-127. Austin: University of Texas Press, 2006.

Rueda Smithers, Salvador. "Emiliano Zapata, entre la historia y el mito". En El héroe entre el mito y la historia, coord. de Federico Navarrete y Guilhem Olivier, 251-264. México: unam, Centro de Estudios Mexicanos y Centroamericanos, 2000. Disponible en: <https://books.openedition. org/cemca/1338?lang=es>.

Vargas Santiago, Luis Adrián. "Emiliano Zapata: cuerpo, tierra, cautiverio”. En El éxodo mexicano. Los héroes en la mira del arte, ed. de Jaime Cuadriello, 440-475. México: Museo Nacional de Arte/unam, 2010. 